\title{
ABRAZANDO LA MAGIA. LA MITOLOGÍA \\ EN EL IMAGINARIO FEMENINO DE \\ LOS RELATOS DE JK ROWLING
}

\author{
Irene C. Marcos Arteaga* \\ Universidad de La Laguna
}

\section{RESUMEN}

Nuestra propuesta plantea profundizar sobre el imaginario de JK Rowling en la creación de los personajes femeninos de la saga sobre Harry Potter, que no sólo se nutre de los obvios mitos grecorromanos, sino de tantos otros que conforman la literatura anglosajona de fantasía. Los estudios de género se han centrado en uno de los personajes centrales de los relatos sobre el joven mago, el de Hermione Granger, aportando sugerentes interpretaciones sobre su creación y sobre los referentes que componen y conforman psicológica y físicamente a la rebelde joven, hasta el punto de transformar las discusiones sobre ello en el centro de los estudios que profundizan sobre la imagen de la mujer en la obra de Rowling. Nosotros queremos no sólo repensar esta figura central de sus relatos, sino al resto de personajes femeninos, moldeados con múltiples referentes de los iconos más evidentes del cosmos mitológico clásico, proponiendo un modelo de estudio y un acercamiento a los referentes creativos de la autora, así como la transformación de éstos en las diferentes adaptaciones cinematográficas, hasta hacerlos formar parte del imaginario cultural de Occidente.

Palabras Clave: Harry Potter, mitología, JK Rowling, arquetipos femeninos, literatura de fantasía, adaptaciones cinematográficas.

\section{EMBRAZING THE MAGIC. THE USE OF MYTHOLOGY IN THE CREATION OF JK ROWLING FEMALE ARCHETYPES}

\section{Abstract}

Our proposal aims to delve into the imagination of JK Rowling in the creation of the female characters in the Harry Potter Saga, which not only inspires on the obvious Greco-Roman myths but also in so many others like Anglo-Saxon fantasy literature. Gender Studies have focused on one of the main characters in the story, Hermione Granger, providing interpretations about her creation and about the references that make up and shape the young rebel, to transform discussions about it into the center of studies that delve into the image of women in Rowling's work. We want to rethink this central figure in her stories and the rest of the female characters in the saga, moulded with multiple referents of the most evident icons of the Classical mythological cosmos, proposing a study model and an approach to the author's creative referents, as well as the transformation of these into different film adaptations, until they become part of the cultural imaginary of the West.

KeYwords: Harry Potter, mythology, JK Rowling, female archetypes, Fantasy literature, film adaptation. 
La literatura fantástica se corresponde con un género que nos ha legado numerosas novelas, cuentos y relatos que están ambientados, generalmente, en mundos o lugares imaginarios en los que, ocasionalmente, la magia y los elementos sobrenaturales forman parte activa de los mismos.

Durante mucho tiempo fue común encontraron este género bajo el paraguas de la literatura de terror o de la de ciencia ficción, pero la fantasía no tiene que compartir las características de la primera o de la segunda; de hecho, las historias adscritas a este género tienen más cosas en común con las novelas de aventuras que con el terror o la propia ciencia ficción.

La literatura fantástica lo que hace es introducir elementos que distorsionan la realidad, además de seres sobrenaturales, tales como magos, brujas, grifos o elfos; creando mundos completamente imaginarios con entidad propia. Los ejemplos más notables y que primero vienen a la mente suelen ser la Tierra Media de Tolkien o el país de Narnia de CS Lewis.

Según Mendelsohn y James (2009), se trata de un género que ha estado presente prácticamente a lo largo de toda la historia de la literatura, aunque lo cierto es que su máxima explosión se daría durante el siglo xx. Sin embargo, para Todorov (2006, citado por Savoye, 2014: 35), el género fantástico tiene que ser considerado como un producto de finales del siglo XVIII, alcanzando su apoteosis durante el XIx para morir a principios del xx, "más evanescente que nunca». Pero entonces, ¿qué sucede con Tolkien o con Lewis? ¿Y con Le Guin o con Rowling? Ferreras Savoye no es de su opinión, pues mantiene que «enterrar lo fantástico con el siglo XIX, incluso a nivel estrictamente literario, no es solamente una exageración: es pura y simplemente un error» (2014: 35).

Como hemos apuntado, el origen del género se remonta hasta la Antigüedad, ya que sus formas se pueden rastrear en los grandes relatos mitológicos, especialmente en los grecorromanos; aunque los nórdicos también han servido de inspiración para muchos autores, como lo fue el poema épico de Beowulf, éste ya de cronología medieval. Todas estas leyendas e historias se suman a los ciclos artúricos y a las novelas de caballería como referentes de gran parte de los autores anglosajones adscritos al fantástico.

En lo que respecta al cine, definir qué adscribimos al de fantasía tampoco ha sido fácil, pues tampoco ha habido consenso al respecto. Como dice Walters, «the search for any kind of definitive answer can often seem only to present more questions. Indeed, the very term 'fantasy' can become troublesome in discussions of cinema» (2011: 1). Al igual que sucede con la literatura, a menudo se han confundido los géneros de ficción y de fantasía en la gran pantalla.

"Discussion of fantasy in terms of genre is made difficult precisely because, despite our recognition of fantasy at work in certain films, it has the innate capacity to seep into different styles, tones and even genres of film making» (Walters,

* Correo electrónico: imarcosarteaga@gmail.com. 
2011: 2). Aun así, si echamos la vista atrás, e independientemente de valoraciones sobre los limes genéricos, hay una serie temática e iconográfica que ha perdurado hasta nuestros días: la idea del viaje (interior y exterior), la magia, las entidades del mal y la lucha contra éstas, los héroes y el espacio del valor personal, o las criaturas fantásticas, entre otras, se tornan en referentes constantes.

$\mathrm{Al}$ igual que sucedió con la literatura, el fantástico ha vivido un resurgimiento bastante reciente gracias a las grandes franquicias hollywoodienses, caso de Harry Potter o Las Crónicas de Narnia, pero también con películas independientes como El Laberinto del Fauno (Guillermo del Toro, 2006), El Imaginario del Doctor Parnasus (Terry Gilliam, 2009), El Hobbit (Peter Jackson, 2012-2014) o El hogar de niños peculiares de Miss Peregrine (2016).

Ya sea en un medio o en otro, el mito se convierte en una parte esencial en la creación de estos mundos imaginarios o «segundos mundos». Así lo apuntaba CS Lewis cuando decía que «... what flows into you from the myth is not truth but reality (truth is always about something, but reality is that about which truth is) and, therefore, every myth becomes the father of innumerable truths on the abstract level. Myth is the mountain whence all the different streams arise which come truths down here in the valley» (Edwards, 2007: 247). Y es que, para él, esos mundos secundarios hacían accesibles explicaciones y reflexiones que de otra manera resultaban bastante difíciles de entender por el lector y espectador medios.

Teniendo todo esto en cuenta, no es de extrañar que los relatos de Harry Potter estén conformados por un conglomerado de referentes entre los que se encuentran la mitología clásica, la nórdica, el folklore británico, el cristianismo, así como algunos elementos asociados a la mitología egipcia. En una entrevista concedida en 2005 a Stephen Fry para la BBC, Rowling afirmaba:

I've taken horrible liberties with folklore and mythology, but I'm quite unashamed about that, because British folklore and British mythology is a totally bastard mythology. You know, we've been invaded by people, we've appropriated their gods, we've taken their mythical creatures, and we've soldered them all together to make, what I would say, is one of the richest folklores in the world, because it's so varied. So, I feel no compunction about borrowing from that freely but adding a few things of my own (https://www.bbc.co.uk/programmes/b0076w0r).

Ante esta afirmación, muchos podrían pensar que la obra de la autora es un mero conglomerado de historias, pero lo cierto es que no se trata de una copia de estos relatos, sino más bien de una asimilación y transformación de sus referentes mitológicos, literarios e incluso religiosos, que en ocasiones nos recuerdan a los utilizados por Tolkien o CS Lewis.

Así pues, el mundo de Harry Potter se conforma mediante la reinterpretación de arquetipos que responden a una estructura narrativa cíclica clásica, que es típica de las historias de los héroes. En ella vemos cómo éste comienza su aventura partiendo de su hogar, vive aventuras, sale victorioso y, finalmente, regresa al lugar al cual pertenece.

En este caso particular, se nos presenta a un huérfano que sufre todo tipo de humillaciones por parte de sus familiares, hasta que recibe la carta que le abrirá 
las puertas de Hogwarts, donde ingresará como estudiante de primer curso. Así comienza su viaje.

Desde que Homero escribiera la Odisea hace casi tres mil años, esta estructura epopéyica se ha ido adaptando al devenir de los tiempos. En el caso concreto de la literatura fantástica, ese modelo cíclico aparece ya en El Señor de los Anillos o en Alicia en el pais de las maravillas, pues sus personajes principales dejan su cotidianeidad para comenzar una aventura que termina con el regreso al hogar. En el primer caso, Frodo abandonará La Comarca para así poder destruir el anillo y salvar a la Tierra Media; en El león, la bruja y el armario, de la saga Las Crónicas de Narnia, los hermanos Pevensie entrarían en un mundo nuevo a través de un armario para derrotar a la hechicera y librar así al país del yugo de ésta. En lo que respecta a Alicia, la niña persigue a un conejo blanco que termina llevándola a un mundo mágico del que, tras vivir numerosas aventuras bastantes locas, termina regresando a casa.

Pero la narrativa de Rowling también puede verse como heredera de las narraciones orales, los cuentos populares y de hadas, que tan de moda se pusieron en la literatura infantil de los siglos XIX y Xx (Burn, 2006: 244). Lo que distingue un relato fantástico de un cuento de hadas es la oportunidad que el autor le brinda al lector para identificar el universo presentado como si fuese suyo para que, luego, intente racionalizar los elementos sobrenaturales que rompen, no sólo con las leyes del mundo tal y como lo conocemos, sino también con la posibilidad misma de conocimiento racional de la realidad (Ferreras Savoye, 2014: 25).

Así pues, tal y como afirma Senabre Sempere, «ninguna obra artística nace de la nada. Brota inevitablemente, de la tradición literaria anterior, bien sea para repetirla o para transformarla y tratar de invocar, de aportar algo nuevo a esa tradición o a la serie literaria que se inscribe» (1992: 32).

En lo que respecta a los arquetipos del género, no son figuras de una sola cara. Todos y cada uno de ellos son poliédricos y, a medida que la historia avanza, se nos van mostrando esos aspectos que componen, en última instancia, al personaje en su totalidad. Esta característica no es exclusiva del protagonista, pues como exponíamos en una publicación anterior en colaboración con el profesor Domingo Sola (2020), «todas las películas de la saga proponen un protagonista modelado a base de fuentes muy diferentes y combinadas, reunidas en una suerte de bricolaje posmoderno".

Por todo esto, no es de extrañar que el universo de Harry Potter esté formado por personajes, tanto masculinos como femeninos, complejos en su definición, así como por una cantidad ingente de criaturas mágicas. Para realizar este paper hemos trabajado únicamente los femeninos, con una selección de los mismos teniendo en cuenta todas las variantes que encontramos en la saga, no sólo abordando a los principales, sino también a aquéllos que los acompañan y que tienen un papel decisivo en la narración; de tal manera que podamos ofrecer un muestreo tipológico mayor.

Por otra parte, queríamos además trabajar tanto sobre el alumnado como sobre el profesorado y, por supuesto, los mortífagos. Probablemente para algunos nuestra selección sea insuficiente, echando de menos a Dolores Umbridge, Nymphadora Tonks, Molly Weasley o Narcisa Malfoy, entre otras; y, aunque todas ellas gozan del mismo peso y/o influencia en la historia, no podemos abarcarlas a todas 
en este trabajo. Por ello, hemos elegido aquéllas que no sólo cumplen con el muestreo, sino que además tienen singularidades en su definición que nos referencian con mayor claridad el origen mitológico de algunos de los elementos que conforman su personalidad o su imagen. Siguiendo estos criterios hemos seleccionado a Hermione Granger, Ginny Weasley, Luna Lovegood y Fleur Delacour, entre el alumnado; Minerva McGonagall, Pomona Sprout y Sybill Trelawney del caustro académico y, finalmente, como representación de las fuerzas oscuras, a Bellatrix Lestrange.

Para sistematizar el trabajo, hemos dividido a los personajes en tres grupos: uno donde colocaríamos aquellos personajes con referentes más obvios entre las mitologías grecorromana, nórdica (entendida ésta como la nórdica en sí misma, la eslava y la germánica) y/o folklore británico. Las calificamos de obvias bien porque la autora haya desvelado la fuente que inspiró a la creación de éste o bien porque éstas sean muy evidentes. Un segundo conjunto de mujeres se agruparía en torno a referencias que son menos, pero que aún están presentes, aunque en menor medida, bien a través de los nombres de elegidos para las mismas o bien por algunos episodios que protagonizan a lo largo de la historia. Y, por último, un tercero, en donde o bien están veladas o inconscientemente hay relaciones con otras mitologías, siendo más difíciles de rastrear.

Según la RAE, un arquetipo es «un modelo original y primario en arte u otra cosa». Pero en su cuarta acepción dice que son «imágenes o esquemas cognitivos con valor simbólico que forman parte del inconsciente colectivo». Uno de los autores que más han profundizado en esta cuestión ha sido Carl G. Jung. En su obra Arquetipos e inconsciente colectivo (1970), el psicoanalista suizo apunta a que el «arquetipo no es una expresión nueva, sino que ya aparece en la antigüedad como sinónimo de idea, en el sentido platónico» (1970: 70).

Pero además de haber servido de campo de estudio a la filosofía, lo cierto es que los arquetipos no sólo son importantes en el arte, sino también en la literatura y el cine. $Y$ es precisamente en estos últimos donde cobran mayor importancia. Jung afirmaba que, «... en los productos de la fantasía se hacen visibles las "imágenes primordiales" y es aquí donde encuentra su aplicación específica el concepto arquetipo» (1970: 73).

Unas líneas más delante, Jung sigue desarrollando este concepto:

Lo mismo ocurre en el caso del arquetipo: en principio se le puede dar un nombre y posee un núcleo significativo invariable que determina su modo de manifestación; pero siempre sólo en principio, nunca concretamente. El modo en que se manifiesta en cada caso el arquetipo de la madre, por ejemplo, no depende de él solamente sino también de otros factores (1970: 74).

Por lo tanto, podemos establecer que los arquetipos, a diferencia de los estereotipos, heredan la forma y no el contenido, como sí sucede con los otros. Muchos de éstos proceden de la mitología grecorromana y normalmente se emplean en la literatura universal o el cine para simbolizar imágenes o emociones universales como el bien, el mal, el amor, la heroicidad, la madre, el padre, etc.

Siguiendo los postulados de Jung, entendemos como arquetipos femeninos aquéllos que contienen elementos pregnantes de otras culturas y mitologías y que 
Rowling enriquece en su desarrollo narratológico, convirtiéndolos en referentes de determinadas potencialidades simbólicas que generan influencia en otros que los rodean. Así pues, este trabajo lo que pretende es analizarlos, ver cuáles se ajustan a los patrones establecidos, si se reinventan o no y de qué manera la escritora británica los modifica y los moldea de acuerdo con la historia del joven mago, para convertirlos en imágenes icono de la cultura occidental por la permeabilidad de su creación y el carácter postmoderno de las mismas.

\section{EL MITO COMO REFERENTE OBVIO}

Siguiendo las subdivisiones propuestas, dentro del primer grupo tendríamos a Fleur Delacour, Minerva McGonagall, Pomona Sprout y Sybill Trelawney.

Fleur Delacour

Fleur was both unequivocally beautiful and distinctly unimpressed by her surroundings.

Pottermore

Fleur estudia en Francia, en la Academia de Magia de Beauxbatons. Aparece en la novela Harry Potter y el cáliz de Fuego y en la película homónima. El cuarto ańo de Harry en Hogwarts coincide con la celebración del campeonato de los Tres Magos. En él, un alumno de cada escuela de magia europea, compite por ganar el trofeo. El objetivo final de éste es que las escuelas que participan (Beauxbatons, Drumstag y Hogwarts) establezcan vínculos entre ellas. En este contexto aparece Fleur como la representante francesa para competir por la copa. Rowling nos la presenta como:

Una chica de Beauxbatons. [...] una larga cortina de pelo plateado le caía casi hasta la cintura. Tenía los ojos muy azules y los dientes muy blancos y regulares (Rowling, 2007).

Esta descripción, junto con las pasiones que despierta en los chicos, podría recordarnos a la diosa Afrodita. Ésta era una divinidad positiva y Fleur también se nos presenta como un personaje positivo, independientemente de las simpatías o antipatías que despierte entre sus compañeras. Ambas mujeres representan la belleza y el deseo.

Además, cuando al llegar por primera vez, las chicas entran en el Gran Comedor, sueltan mariposas, que se confunden con aves. Estos animales nos recuerdan a uno de los atributos de la diosa griega, la paloma. No tanto por su relación, que obviamente no la tiene, sino porque podría establecerse un paralelismo con las divinidades aéreas; de hecho, Fleur llega a Hogwarts en una carroza tirada por caballos alados, lo que no parece una casualidad (figs. 1, 2 y 3 ). 
Pero las referencias no sólo se quedan circunscritas a la mitología grecorromana. Dentro del texto literario, Rowling revela su fuente de inspiración para este personaje: «... la chica que parecía una veela se puso en pie elegantemente, sacudió la cabeza para retirarse hacia atrás la amplia cortina de pelo plateado...» (2007). Las veelas son unas figuras mitológicas de la cultura eslava. Éstas son

seductive nature spirits originate in legends of Central Europe. They are beautiful young women -or appear to be such. In some stories they are said to be ghosts of unbaptized women whose souls cannot leave earth. Their beauty is astonishing and can make men act foolishly. They have long hair, so fair it seems white. [...] What upsets veela most is having their ritual dances disturbed (Colbert, 2008: 245, 248).

Esta descripción coincide con el momento tras el que son presentadas, ya que entran realizando una especie de baile que hipnotiza a toda la escuela, especialmente por la belleza de todas ellas.

Minerva McGonagall

Professor McGonagall, the strict but sentimental Transfiguration teacher, plays a major role in Harry's life right from his first day at Hogwarts.

Pottermore

Una de las figuras más destacadas del claustro de profesores de Hogwarts es Minerva McGonagall. Es la subdirectora del colegio, además de jefa de la casa de Godric Griffindor, e imparte la asignatura de Transformaciones. La elección del nombre de una de las diosas romanas para una de las directoras de una de las casas más importantes de la saga no es gratuita. Rowling no sólo dota a este personaje del nombre de una de las diosas más importantes del panteón romano, sino que las cualidades psicológicas de la misma se ajustan a las descripciones que de ella nos han llegado desde la época antigua. De la diosa se decía que «era alta, de rasgos serenos, más majestuosa que bella, siendo tradicionalmente descrita como "la diosa de ojos garzos"» (Grimal, 2008: 61). En esta línea, en la primera novela, Harry Potter y la piedra filosofal, se nos presenta así a la profesora McGonagall:

... dirigía la sonrisa a una mujer de aspecto severo que llevaba gafas de montura cuadrada, idénticas a las líneas que había alrededor de los ojos del gato. La mujer también llevaba una capa, de color esmeralda. Su cabello negro estaba recogido en un mońo. Parecía claramente disgustada (Rowling, 1997).

Las pocas descripciones que Rowling nos ofrece de ella pivotan sobre la misma idea: una mujer recta, severa, exigente, cuyos ojos eran tan expresivos que no hacía falta que dijese nada. Pero no sólo tiene en común con la diosa romana los rasgos psicológicos, pues la protección que McGonagall ejerce sobre Harry a lo largo de todas y cada una de las novelas y películas recuerda a la protección que ésta ejerció sobre Heracles y Ulises. 
Que Minerva sea capaz de transformarse en gato no es gratuito. Según Carla Cingolani,

another feature that can be connected to these aspects of her personality is the fact that she can turn into a cat, which brings about wider possibilities for the reader to interpret this character's personality. Stoic, silent and mysterious and associated with magic since ancient times, cats' symbols allow readers to place Professor McGonagall's character among those symbols they represent cleverness, independence and intuition»(Cingolani, 2012: 28) (figs. 4, 5, 6 y 7).

A pesar de ello, el poder de transformación o de transfiguración no fue algo privativo de la mitología grecorromana -de sobra son conocidas las múltiples formas que Zeus/ Júpiter adoptaría para engañar a las mujeres según se recoge en Las Metamorfosis de Ovidio-. En la saga de Harry Potter encontramos dos maneras de poder obtener una transfiguración total: la primera se realiza mediante la elaboración y toma de una poción llamada "multijugos», y la segunda, siendo un ani$m a g 0^{1}$. Dentro de este segundo grupo encontramos a Peter Pettigrew y a Minerva; el primero con la capacidad de convertirse en rata y la segunda en gato. Recordemos que los animagos no eligen el animal en el que quieren convertirse. Su forma está determinada por su personalidad y rasgos internos. También es posible que el patronus corpóreo de cada bruja o mago indique en qué convertirse; así, el patronus de Minerva es un gato o el de James Potter un ciervo (figs. 8 y 9).

Esta capacidad de transformación, aunque en sentido inverso, podría tener relación con los cuentos tradicionales provenientes del norte de Europa, en donde se hablaba de una criatura mitológica procedente de las Islas Feroe, así como de Islandia, Irlanda y Escocia: los selkie. De ellos se decía que tenían la apariencia de focas y que podían transformarse en mujeres y hombres y adentrarse en la tierra. La leyenda cuenta que, si algún humano encontraba la piel de foca, podía desposar al selkie (Stone, 2016).

Por otra parte, las brujas que cambiaban de forma siempre formaron parte del folklore británico durante siglos. De ellas se decía que si eran heridas mientras estaban en su forma animal, la herida permanecería cuando volviesen a su forma humana. Este hecho permitió identificar a aquellas personas de las que se sospechaba que eran brujas (Waltz, 2016: 211). Aunque esta característica del folklore británico no aparece en ella, ya que no combatió en las Guerras Mágicas ${ }^{2}$ en su forma animal.

${ }^{1}$ Animago: es un mago o una bruja con capacidad de transformarse en un animal, conservando el pensamiento humano y la capacidad de razonar, aunque no de hablar. No se trata de una capacidad innata, sino más bien de una habilidad mágica. Se trata de un proceso largo y arduo, que en muchas ocasiones no suele salir bien.

${ }^{2}$ Cuando hablamos de las Guerras Mágicas nos referimos a la Primera y Segunda Guerra Mágica. Ambas fueron conflictos en donde se enfrentaron las fuerzas del bien contra las del mal. En la primera contienda, Voldemort, junto con sus mortífagos, comenzaron atacando a los muggles para después empezar a exterminar familias enteras de magos. Tras la derrota de los gigantes contra los aurores, se produjo el final de esta, en 1981, y, por tanto, culminó con la «derrota» de Lord Vol- 
With her ramshackle patchwork hat, mad flyaway hair and soil-encrusted nails, the jovial professor wasn't just green-fingered, but integral to the Hogwarts staff and surprisingly handy in a scrape. Pottermore

Es la jefa de la casa de Hufflepuff y profesora de la asignatura de Herbología. Su papel en la narración no es constante, pero sí determinante en algunos momentos.

Su nombre es el de una ninfa romana que velaba sobre los frutos. Ovidio la presenta como la esposa de Vertumno, relacionada con el ciclo de las estaciones y la fecundidad de la tierra (Grimal, 2008: 446); pero su filiación con la mitología clásica no sólo se reduce a su nombre, sino también a su apariencia. Sabemos que las ninfas eran deidades menores asociadas a elementos naturales, y de la profesora Sprout se afirma que «era una bruja pequeña y regordeta [...] y que, gracias a ella, los alumnos aprendían a cuidar de todas las plantas extrañas y hongos y a descubrir para qué debían utilizarlos» (Rowling, 1997) (fig. 10).

Según Grimal, Homero aseveraba que solían acompañar a los dioses, especialmente a Artemisa. En este sentido, la profesora Sprout es muy buena amiga de la profesora McGonagall, apoyándola en su enfrentamiento con Dolores Umbridge cuando ésta es nombrada directora de Hogwarts.

Sybill Trelawney

(...) Sybill has cultivated a dramatic manner and enjoys impressing her more gullible students with predictions of doom and disaster. JK Rowling

Encarnada en la pantalla por la actriz Emma Thompson, la profesora Trelawney imparte la asignatura de Adivinación. Superficialmente, Sybill parece estar siempre despistada, siendo incapaz de acertar en sus predicciones, ni siquiera en las lecturas de los posos del té. No es respetada por algunos magos y brujas; incluso, Hermione desdeña su asignatura; pero lo cierto es que sería ella quien predijese la profecía que acabaría con Lord Voldemort.

De ella Rowling nos dice que «era sumamente delgada. Sus grandes gafas aumentaban varias veces el tamaño de sus ojos y llevaba puesto un chal de gasa con lentejuelas. De su cuello largo y delgado colgaban innumerables collares de cuentas, y tenía las manos llenas de anillos y los brazos de pulseras» (1999) (figs. 11 y 12).

demort. Respecto a la seguda, varios acontecimientos como la Batalla en la Torre de Astronomía, la Batalla sobre Little Whinging o la desaparición misteriosa de algunos magos, entre otros, propiciaron la Segunda Guerra Mágica, también conocida como la Batalla de Hogwarts. 
Su nombre deriva de las sibilas, mujeres sacerdotisas que se encargaban de anunciar los oráculos de Apolo. La más célebre de todas ellas fue la de Eritras, que posteriormente llegó a Cumas. De ella «se contaba que habiendo pedido una larga vida a Apolo, que la amaba y había prometido concederle la satisfacción del primer deseo que expresara, se había olvidado de pedirle al mismo tiempo la juventud. El dios se la ofreció a cambio de su virginidad, pero ella rehusó. Así, a medida que envejecía, iba volviéndose más y más menuda y seca, hasta que terminó pareciendo una cigarra, y la encerraron como un pájaro en una jaula [...]» (Grimal, 2008: 478-479). Es ésta una descripción muy parecida a la que encontramos en la quinta entrega de la saga sobre Sybill, donde se insiste en lo estrafalaria que es, además de que a Harry le recordaba a una «especie de insecto por las gruesas gafas que llevaba, que aumentaban de tamaño sus ojos» (Rowling, 2003), lo que estrecha aún más el lazo con la de Cumas.

Su relación con la mitología no sólo se ciñe al nombre, sino que sus raíces se hunden más de lo que el lector puede pensar. Su tatarabuela fue Cassandra Trelawney, una bruja muy famosa y vidente, también profesora en Hogwarts, de Adivinación. No resulta casual que este antepasado de Sybill se llame así, pues recordemos que Cassandra fue una princesa troyana a la que Apolo le concedió el don de la profecía, siendo una joven muy talentosa, inteligente y sumamente bella. El dios se enamoraría de ella hasta tal punto que, cuando fue rechazado por la joven, éste la maldijese: Cassandra podía seguir viendo el futuro, pero estaba condenada a que nadie la creyese.

Todas estas cualidades no dejan de recordarnos a su personaje, quien, en palabras de Rowling, «the problem with Sybill is that she doesn't seem to have a good grasp of her gifts, which leads her to misinterpret the things she sees or reads in tea leaves» (2020). Por tanto, ambas parecen marcadas por un halo de incomprensión y por un evidente desdén hacia su persona.

\section{EL MITO COMO SUTIL REFERENCIA}

Por otro lado, hay personajes cuya filiación mitológica es más difusa, pero aún identificable, bien a través de los episodios que protagonizan, o bien por el desarrollo de su psicología. Entre ellos estarían Ginny Weasley y Luna Lovegood.

\section{Ginevra «GinnY» Weasley}

Ginny had an immensely strong spirit across the Harry Potter books, so strong in fact that Harry Potter himself began to notice after a while. JK Rowling

Aunque las novelas no nos ofrecen claras descripciones de la muchacha, sabemos que al ser la hija pequeña del matrimonio Weasley, debe ser pelirroja y pecosa, 
como sus hermanos mayores. Su personaje crece según se desarrolla la historia, convirtiéndose en parte activa de la misma, pues como señalábamos en una publicación anterior (2019), su episodio en la Cámara de los Secretos marcaría un antes y un después en la construcción de su personaje, ya que durante su primer año en la escuela sería hechizada por Lord Voldemort para cometer una serie de estragos en el colegio que terminarían con su rapto en la Cámara de los Secretos. Este hecho hizo que Ginny cambiase radicalmente. Dejó de ser la hija de la señora Weasley o la hermana de Ron, un personaje pasivo, para transformarse en una protagonista proactiva, desarrollando una personalidad propia y unos poderes que la convertirían en una bruja excepcional, como se aprecia con más claridad desde la quinta novela, y película, en adelante (figs. 13 y 14).

En su gestación convergen varios referentes del corpus mitológico grecorrromano. Su papel en la narración podríamos dividirlo en dos etapas: una anterior a la escena de la Cámara de los Secretos y otra posterior a la misma. En la primera, en Ginny se nos ofrecen reminiscencias claras de Eurídice y Perséfone. Ambas tienen en común con la joven Weasley que, con anterioridad al rapto por parte de Aristeo y Hades, las tres eran amantísimas hijas. Además, todas serían reclamadas; una por su madre Deméter, otra por su amado Orfeo y Ginny por Harry; quien descendería a la cámara como si fuera el augur y profeta, hijo de Apolo y Calíope, en busca de ella.

Más sutil es la relación de Ginny con la diosa egipcia Sekhmet. Conocida como «la invencible» o «la terrible», no es gratuito que el rostro de ésta sea el de una leona coronada por un disco solar. Ginevra forma parte de la casa de Griffindor, cuyo símbolo es el mismo animal, y, además, los griffindors ${ }^{3}$ comparten con esta diosa cualidades como la fuerza o el poder, entendido éste como el que emana de una voluntad férrea. El disco solar, aun sin un elemento iconográfico paralelo con la imagen que proyecta la joven en los filmes, podría relacionarse con un símbolo de la pureza de los Weasley, pues éstos forman parte de una de las familias de sangre pura, junto con los Malfoy o los Black.

En el imaginario egipcio, el disco solar estaba vinculado a la realeza y Sekhmet, además, se presenta como protectora de los faraones y guía de éstos durante el combate militar. Pues bien, en paralelo Ginny se uniría al Ejército de Dumbledore y se convertiría en parte activa de la causa de Harry y del mundo mágico para derrotar a Lord Voldemort. Durante las reuniones de este grupo, Ginny sobresaldría en la práctica de hechizos y, además, combatiría con mortífagos adultos y más experimentados que ella, como así sucedería en la Batalla del Departamento de Misterios. Su carácter protector hará que, junto con Hermione y Luna, se encarguen de proteger a Harry. Por tanto, ambas son figuras protectoras, relacionándose con el enfrentamiento contra el mal en su intento de mantener el orden.

Sin lugar a duda, hay otras Ginevras en la historia, en los mitos y en el folklore británico. Evidente es su relación, al menos en cuanto al nombre, con la reina

3 Se denominan griffyndors a aquellas personas que pertenecen a la casa de Godric Griffyndor, uno de los cuatro fundadores de Hogwarts. 
Ginevra, mujer del Arturo. Decimos aparentemente porque si prestamos atención a la historia que envuelve a la reina, poco o nada tiene que ver con la de la bruja. E igual de débiles nos parecen las aparentes relaciones entre la Ginevra de Sir Edward Bulwer-Lytton ${ }^{4}$, ya que en su poema "The Fairy Bride», la novia sólo comparte el nombre también, pues habla de la unión de un joven caballero con una joven hada/ elfina. Y más lejanas aún parecen quedar las relaciones que pudiera tener con la reina como epítome del amor cortés de la literatura caballeresca medieval.

\section{LUNA LOVEGOOD}

Luna was 'the anti-Hermione. Hermione's so logical and
inflexible in so many ways and Luna is likely to believe ten
impossible things before breakfast'.
JK Rowling

Luna aparece por primera vez en la quinta novela de la saga, aunque su ingreso en Hogwarts se produce el mismo año que Ginny Weasley y su protagonismo en la narración va in crescendo a medida que nos acercamos al final de la serie.

De ella la autora dice:

Tenía el pelo rubio, sucio y desgreńado, largo hasta la cintura, cejas muy claras y unos ojos saltones que le daban un aire de sorpresa permanente [...]. La muchacha tenía un aire inconfundible de chiflada. Quizá contribuyera a ello que se había colocado la varita mágica detrás de la oreja izquierda, o que llevaba un collar hecho con corchos de cerveza de mantequilla, o que estaba leyendo una revista al revés (Rowling, 2003).

En este personaje convergen varias divinidades del cosmos clásico como Selene o Éter. La primera-inherente a su nombre-, era la personificación de la Luna y recorría el cielo montada en un carro de plata tirado por dos caballos. En Harry Potter y la Orden del Fénix la señorita Lovegood acompaña a un thestral, criatura muy parecidas al caballo cuya anatomía dejaba ver el esqueleto del animal, poseyendo, además, unas alas similares a las de un murciélago. Por tanto, ambas transitan acompañadas por equinos (fig. 15).

Por otro lado, la candidez y la luz que desprende, no sólo la apariencia física de Luna sino su manera de ser y entender el mundo, la conecta con Eter, personificación del cielo superior, donde la luz es más pura (Grimal, 2008: 180).

Obviamente, la personalidad excéntrica de Luna hace que la relacionamos con la profesora Trelawney y, por ende, con las sibilas, como ya hemos apun-

${ }^{4}$ Sir Edward George Earle Bulwer-Lytton (1803-1873) fue un poeta, novelista, dramaturgo, político y periodista británico. Lytton fue un popular escritor de su tiempo que acuñó expresiones como «La pluma es más fuerte que la espada». Pero quizás la más famosa sea: «Era obscura y tormentosa la noche...». 
tado con anterioridad. Y es que su «comportamiento y personalidad [...] se aparece a las figuras de las diosas/sacerdotisas/profetisas romanas que iluminan la oscuridad y ofrecen una visión única y enigmática». Precisamente esa manera de hablar, su visión de la realidad, «su don para la adivinación y sus desconcertantes respuestas parecen relacionarla con estos antiguos videntes grecorromanos», como bien expone Richard Spencer (2015: 96).

\section{EL MITO VELADO}

Finalmente, podemos establecer un tercer grupo de mujeres en las que los referentes que manejamos están o bien velados o son tan difusos que en su análisis entran en juego más factores aparte de la etimología del nombre, su descripción física y psicológica, o los episodios en los que participan en la narración. Entre ellos estarían dos protagonistas antagónicas, la heroína, Hermione Granger, y la antagonista, Bellatrix Lestrange.

\section{Hermione Granger}

Hermione may have been the brightest witch of her age (...) JK Rowling

Es una de las protagonistas más notables y sobresalientes de la saga; tanto que ha sido objeto de numerosos estudios, sobre todo desde la teoría de género. Desde el primer momento, Rowling siempre ha afirmado que para crearla se basó en ella misma, estudiosa y obsesionada por los libros (Richards, 2003: 5).

Pero también es cierto que comparte nombre con la hija del rey Menelao y de Helena de Troya, una mujer hermosa, como lo era su madre; atributos físicos que a priori no comparte con la protagonista de la saga. Hasta la celebración del Baile de Navidad en la cuarta novela, Harry Potter y el cáliz de Fuego, de Hermione Granger se dice que «tenía voz de mandona, mucho pelo color castańo y los dientes de delante bastante largos» (Rowling, 1997); ningún epíteto especialmente relacionado con la belleza homérica.

Como ya hemos visto, Rowling sigue en su empeño de no ahondar en la feminidad de sus mujeres ni en describir sus rasgos sexuales, al menos en las primeras novelas; algo que cambiará en la segunda mitad de la saga. Hasta ese momento se incidía en el aspecto intelectual de la joven y en algunos rasgos físicos obvios. Sin embargo, la transformación en ese baile será evidente:

Era Hermione. Pero estaba completamente distinta. Se había hecho algo en el pelo: ya no lo tenía enmarańado, sino liso y brillante, y lo llevaba recogido por detrás en un elegante moño. La túnica era de una tela añil vaporosa, y su porte no era el de siempre, o tal vez fuera simplemente la ausencia de la veintena de libros que solía cargar a la espalda. Ella también sonreía (con una sonrisa nerviosa, a decir verdad), 
pero la disminución del tamaño de sus incisivos era más evidente que nunca. Harry se preguntó cómo no se había dado cuenta antes (Rowling, 2000: 365).

Este cambio físico despierta el interés en Viktor Krum, provocando un ataque de celos de Ron, enamorado de ella desde tiempo atrás. Toda esta situación la cosifica y la convierte en objeto de deseo (Ehrenheim, 2016: 31); aunque a su favor habría que decir que siendo la única chica del colegio que mostrase desinterés por el joven húngaro, hace que él se fije en ella. Este episodio de celos nos recuerda a la rivalidad nacida entre Orestes y Neoptólemo; similitud que haría plausible que la princesa griega hubiese servido de inspiración para configurar paralelamente este personaje (figs. 16 y 17).

Sin embargo, su inteligencia, planificación y previsión hace que psicológicamente nos recuerde a Atenea, diosa de la sabiduría. Tanto ésta como Hermione intentan proteger a los héroes de la historia; Harry en el primer caso, y Heracles y Perseo, en el segundo. Por ejemplo, en Harry Potter y la Cámara de los Secretos, Hermione le proporciona a Harry un trozo de espejo con el cual consigue eludir la mirada directa del basilisco. Algo similar sucede con Atenea y Perseo, pues la diosa le entrega al joven héroe un escudo brillante para luchar contra Medusa. En ambos casos, ese ardid es necesario porque tanto el basilisco como la Gorgona provocaban la muerte directa en aquéllos que los miraban a los ojos.

A pesar de estas relaciones, Hermione es una especie de profesora McGonagall pero sin la rigidez de ésta. Como bien dice Rowling (2017), su ética del trabajo, así como su absoluta disposición a hacer lo que ella creía correcto, resultan inspiradoras para muchas personas.

\section{Bellatrix Lestrange}

She was one of the most terrifying characters from the books and actress Helena Bonham Carter brought this formidable Death Eater to life in menacing style.

JK Rowling

Bellatrix Lestrange pertenece a una familia de sangre pura, los Black. Era prima de Sirius Black y hermana de Narcissa Malfoy. Su relación con el mito es más compleja, quizás, que en otros personajes femeninos. Por un lado, su nombre procede el latín y significa "guerrera», pero también hace referencia a una estrella de Orión.

$\mathrm{Si}$ atendemos a su historia personal, además de conocer su ascendencia, sabemos que se casaría con Rodolphus Lestrange para mantener la pureza de sangre, uniéndose bien pronto a los mortífagos, hecho que la llevará a pasar numerosos años encerrada en Azkaban (figs. 18 y 19).

Su único amor era Lord Voldemort, un amor unilateral que la consumiría (Rowling, 2018), ya que el innombrable era incapaz de querer a nadie. Esta referencia la emparenta, en cierta medida, a la historia entre Hades, dios del Inframundo, y Perséfone. Por supuesto, hablamos del lado oscuro de Perséfone como reina del Inframundo, aquélla que es retratada como un ser implacable con aqué- 
llos que llegaban al Hades, sintiendo sólo compasión por Orfeo, en su descenso en busca de Eurídice.

Más plausible es su relación con la celta Morgana, reina de la isla de Ávalon, una de las hechiceras más poderosas de la literatura occidental. Al igual, Bellatrix, para muchos, constituye una clara personificación del mal, del odio, de la venganza, así como del poder de la belleza y del deseo. La leyenda nos cuenta que además podía convertirse en cualquier animal, así como persuadir a las personas no mágicas, ver el futuro y alterarlo. Por su parte, Bellatrix también destacó en varias de estas prácticas, siendo muy habilidosa empleando la magia no verbal, enseñando oclumancia $^{5}$ a su sobrino Draco Malfoy. Por ello, parecen cruzarse evidentes relaciones entre ambas figuras.

Durante la Edad Media el cristianismo tuvo dificultades para asimilarla, quizás por ello se fue volviendo cada vez más y más siniestra hasta que finalmente se la representó como la conocemos hoy en día: una bruja discípula de Merlín, quien le enseñaría las artes oscuras; convirtiéndose en el tormento del rey Arturo y de sus caballeros, especialmente de la reina Ginevra.

Pero también existen diferencias entre Morgana y Bellatrix. Las fuentes dicen de la primera que en sus orígenes había sido una joven buena que poco a poco se había ido envenenando. Por su parte, la mortífaga procedía de una familia de sangre pura y racista, y desde bien joven defendería las tesis de la supremacía de la raza mágica, desdeñando cualquier tipo de criatura que no fuese mago o una bruja. Hasta su entrada en Azkaban, tras la Primera Guerra Mágica, se dice de ella que era una joven bella, como todas las hermanas Black; sin embargo, su encierro hizo que desmejorase físicamente, llegando a desarrollar una personalidad bastante inestable y desquiciada; $y$, al igual que Morgana con Arturo, Bellatrix se convirtiría en uno de los azotes personales de Harry Potter a lo largo de la saga, muriendo a sus manos personas muy importantes para éste, como fueron Sirius Black (su padrino), Dobby o Nymphadora Tonks.

En nuestra interpretación, ambas realizan un viaje emocional/psicológico. En el caso de Morgana, desde el bien hacia el mal; mientras que Bellatrix lo hace desde la belleza a la fealdad; lo que metafóricamente no deja de ser un proceso simbólico, reflejo del envenenamiento de la personalidad. Por lo tanto, ambas terminan de adultas alineadas con las fuerzas del mal, tras un continuo, azaroso y duro viaje emocional.

Mención especial merece la caracterización de Morgana, tanto en la grande como en la pequeña pantalla. Como se puede observar en la figura 21, Helena Boham Carter, en 1998, encarnaría a la hechicera en una miniserie dedicada a Merlín, siendo curioso cómo su caracterización se parece muchísimo a la de Bellatrix Lestrange. Además, ambos personajes parecen estar inspirados en un lienzo de John

5 La oclumancia es una rama oscura de la magia. Consiste en cerrar la mente contra la rama opuesta, la legeremancia. Esta técnica impide el acceso a los pensamientos y sentimientos a un legeremántico. Requiere de una gran fuerza de voluntad y de un alto nivel de disciplina mental. 
William Waterhouse (1849-1917) titulado El círculo mágico. Aunque nada indica expresamente que se trate de la bruja Morgana, lo cierto es que, en él, el pintor británico nos presenta a una mujer que parece ser una bruja "o sacerdotisa dotada de poderes mágicos en el poder de la profecía». En cuanto a sus atributos, «en su mano izquierda sostiene una hoz en forma de media luna, algo que la conecta con la Luna y Hécate. Con la varita en su mano derecha dibuja a su alrededor un círculo mágico protector. Fuera del mismo, el paisaje está desnudo y estéril. Sólo vemos un grupo de torres o cuervos y una rana, todos símbolos del mal y asociados a la brujería. Pero dentro de sus límites están las flores y la mujer, ambas como objetos de belleza ${ }^{6}$ (Fowle, 2000) (figs. 20, 21 y 22).

Pero quizás con quien más concomitancias encontremos sea con la figura de Lilith. Según la tradición hebraica, ella fue la primera mujer de Adán, creada antes que Eva y de diferente manera, pues Lilith nació del polvo, no queriendo someterse a las pretensiones de Adán, sobre todo en las referidas a las relaciones sexuales. Adán intentó someterla provocando la ira de la joven, que encolerizada, llamó a Dios, se elevó en el aire y le abandonó, pasando un tiempo entre demonios, con los cuales engendraría a toda una estirpe.

Por lo tanto, Lilith es una fémina insubordinada y rebelde, características que definen el carácter explosivo de Bellatrix y, además, poseía una gran belleza coronada por una hermosa cabellera, símbolo de la lujuria y, por lo tanto, del pecado y del mal (Bornay, 2009: 46). Obviamente, el confinamiento en Azkaban hizo mella tanto en el físico como en la mente de Bella, pero observando a su hermana Narcissa, no sería de extrañar que, en su juventud, Bellatrix fuese una joven muy hermosa.

No tenemos la certeza de que nuestro personaje fuese la primera mujer del lado oscuro. La igualdad entre ambos géneros dentro del mundo mágico está presente desde la fundación del Colegio Hogwarts de Magia y Hechicería, viendo en todas las películas un equilibrio entre los personajes femeninos y masculinos en los puestos de poder, lo que les genera respeto y admiración. Ejemplo de ello serían los cuadros que hay en el colegio de todos los directores y directoras que han pasado por el mismo. Además de los fundadores de las cuatro casas, Griffyndor, Slytherin, Ravenclaw y Hufflepuff cuentan con dos hombres y dos mujeres: Godric Gryffindor, Salazar Slytherin, Rowena Ravenclaw y Helga Hufflepuff.

Sin embargo, es un hecho que ella es la primera que aparece en la historia como una guía. Bella es capaz de liderar, someter, y de infligir castigo y miedo en los seguidores de Lord Voldemort, a los que dirige cuando éste no está. Es cierto que, en la saga de Animales Fantásticos y dónde encontrarlos, hay mujeres que combaten en el lado de Gellert Grindelwald pero, hasta la fecha, en ninguna de las dos

${ }^{6}$ «Or priestess, endowed with magic powers, possibly the power of prophecy». En cuanto a sus atributos, «in her left hand she holds a crescent-shaped sickle, linking her with the moon and Hecate. With the wand in her right hand she draws a protective magic circle round her. Outside the circle the landscape is bare and barren; a group of rooks or ravens and a frog-all symbols of evil and associated with witchcraft- are excluded. But within its confines are flowers and the woman herself, objects of beauty». 
películas estrenadas observamos un personaje femenino de la presencia, psicología y poder de Bellatrix Lestrange.

Como hemos visto, Rowling mezcla elementos procedentes de diversas fuentes y con total libertad, tal y como lo hizo CS Lewis en Las Crónicas de Narnia, plasmando temas universales que siempre habían preocupado al ser humano, como la lucha entre el bien y el mal, la muerte, la amistad o el amor, entre otros. Además, como afirma Burn:

What the Potter phenomenon demonstrates is the value of a popular, cross-media, mythopoeic complex of narratives, which children can use to explore the growth of identity, the nature of their social roles, the power of fantasy, and the pleasure of participatory story (2006: 247).

Así pues, los vestigios que quedan de todos estos modelos prototípicos han llegado hasta nuestros días a través de la mitología (Guil Bozal, 1998: 95) y, gracias a ella, podemos enfrentarnos y manejar los conflictos humanos básicos, por ejemplo, la muerte.

Pero los arquetipos también influyen en los estereotipos que hay sobre la mujer. En un trabajo de Guil Bozal (1998), reflexiona sobre cómo los arquetipos de género siguen estando presentes en la sociedad occidental, «condicionando de forma importante el papel de los hombres y de las mujeres» (1998: 95). Por un lado, en esta línea encontramos trabajos como el de Francisca y Mochtar, The role of Girls as Mothers in Harry Potter Series. En él subrayan que Hermione, Ginny y Luna adoptan el rol de madre. Su argumentación descansa en la teoría de Barthes sobre dos estereotipos: las niñas tienen que ser madres y las madres deben proteger, nutrir y educar. Para sus autoras, Rowling "cannot escape the myths on girls and women. She sees that being a mother is the most powerful role for girls and women» (2017: 1).

Asimismo, es interesante ver cómo la incorporación de la mujer a la esfera pública, «desempeñando roles fuera de los arquetípicamente atribuidos a su condición femenina, se ha tenido de alguna manera que masculinizar» (Guil Boza, 1998: 98). Siguiendo esta línea, nos encontramos un trabajo coreano, Feminist Revision of Epic Tradition in JK Rowling's Harry Potter, que subraya esta idea de la masculinización en el personaje de Hermione Granger. En un capítulo dedicado al arquetipo de las madres, afirma que el punto fuerte de la joven bruja «is conventionally considered masculine qualities» (2018: 38); y añade:

In the portrayal of Hermione, there is a strong sense of gender reversal. The only girl in the trio with nurturing instincts takes care of her friends with her logic, intelligence, and wit, which, in the patriarchal convention, all belong to the masculine domain. With her gender-ambivalent representation of a symbolic mother, Rowling provides another example of androgynous revision of motherhood (2018: 38).

Por otro, Kylie Smith afirma que, a pesar de que los personajes femeninos están sujetos a la convención y construcción de género, los personajes femeninos no son pasivos ni invisibles. Para Smith, las mujeres de la saga "go against gender conventions on a regular basis, especially with regards to what may be considered feminine traits» (2008: 666). 
Sea como fuere, los arquetipos y estereotipos se perpetúan. El debate es amplio y, como hemos visto, encontramos opiniones muy diferentes en cuanto al papel que juegan éstas y otras mujeres en la historia, pues, a pesar de que los tres grandes protagonistas son hombres, Harry, Albus Dumbledore y Lord Voldemort, lo cierto es que las novelas presentan una gran variedad de personajes femeninos que adquieren un mayor protagonismo en la narración a partir de la quinta novela, Harry Potter y la Orden del Fénix -a excepción de la profesora McGonagall o de Hermione Granger, importantes desde la primera novela y nunca subordinadas a las acciones del protagonista, sino compañeras del mismo-. Aunque, desde nuestro punto de vista, tras la aparición de Ginny Weasley en la segunda novela y su descenso al Hades, se apuntale el papel femenino dentro de la saga.

A diferencia de Tolkien, y según lo que hemos podido analizar en estas líneas, las mujeres en la saga del «niño que sobrevivió» son más numerosas, independientes y poderosas. Mientras que Arwen o Eowyn están supeditadas a sus padres, Hermione, McGonagall o Lestrange no dependen de nadie, siendo parte activa de la historia, convirtiéndose, en muchas ocasiones, en personajes que determinan el éxito o el fracaso de Harry. Es por ello por lo que muchos investigadores se preguntan si la saga de Harry Potter puede considerarse o no una saga feminista.

Todas las mujeres que conforman el cosmos potteriano desarrollan identidades independientes y fuertes, son habilidosas en la magia, especialmente en el campo en el que se especializan. Además, toman decisiones por sí mismas y tienen pensamientos éticos y políticos propios. Véase por ejemplo cuando Hermione decide defender a los elfos domésticos creando la $\mathrm{PEDDO}^{7}$, o cuando Luna Lovegood le dice a Harry que tanto ella como su padre han tomado partido por el bando del joven mago, en lugar de estar a favor de las políticas del Ministerio de Magia o de doblegarse ante el Señor Tenebroso. En estas líneas podemos afirmar, tal y como expone Mimi Gladstein, que las mujeres en el mundo de Harry Potter son cualquier cosa menos ciudadanas de segunda clase (2017: 49).

Por lo tanto, más que de una saga feminista podríamos afirmar que las mujeres de la saga se representan fuertemente empoderadas a lo largo de toda la historia.

Recibido: mayo de 2020; ACEPTAdo: junio de 2020

7 La PEDDO es la Plataforma Élfica de Defensa de los Derechos de los Obreros. Fue creada por Hermione Granger para defender los derechos y cuestionar la posición de la ley de magos y la Legislación de los Elfos, después de presenciar cómo maltrataban a Winky, una elfina. Granger creía que era injusto y cruel que a los elfos domésticos no les pagaran ni recibiesen vacaciones por su trabajo, por lo que hizo campaña para cambiar sus condiciones laborales. 


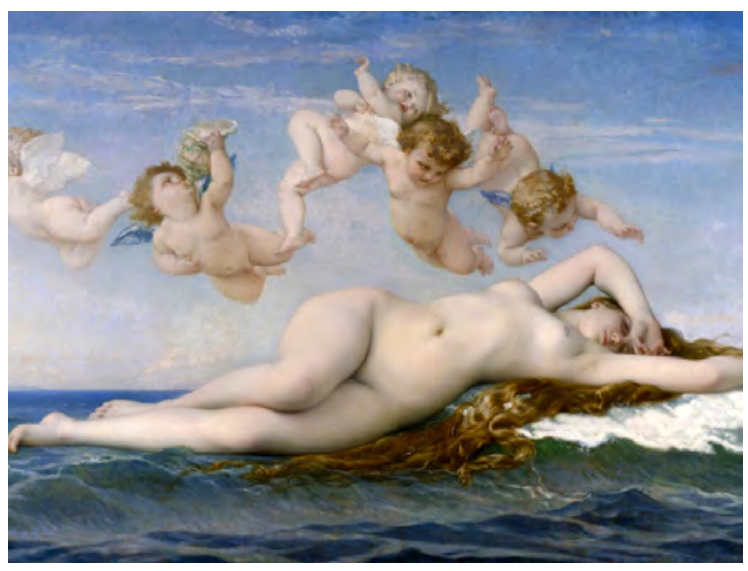

Fig. 1. El nacimiento de Venus. Alexandre Cabanel, 1863.

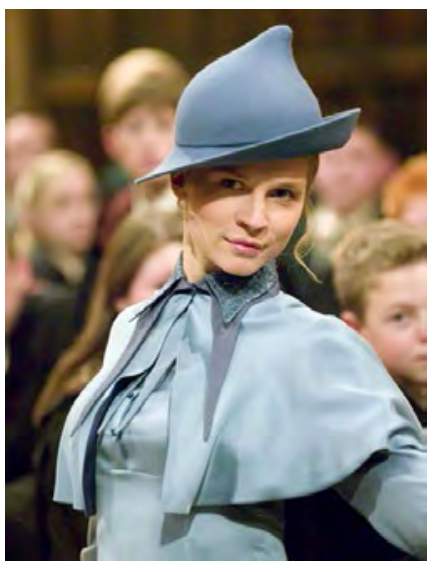

Fig. 2. Fleur Delacour. Fotograma de Harry Potter y el Cáliz de Fuego, 2005.
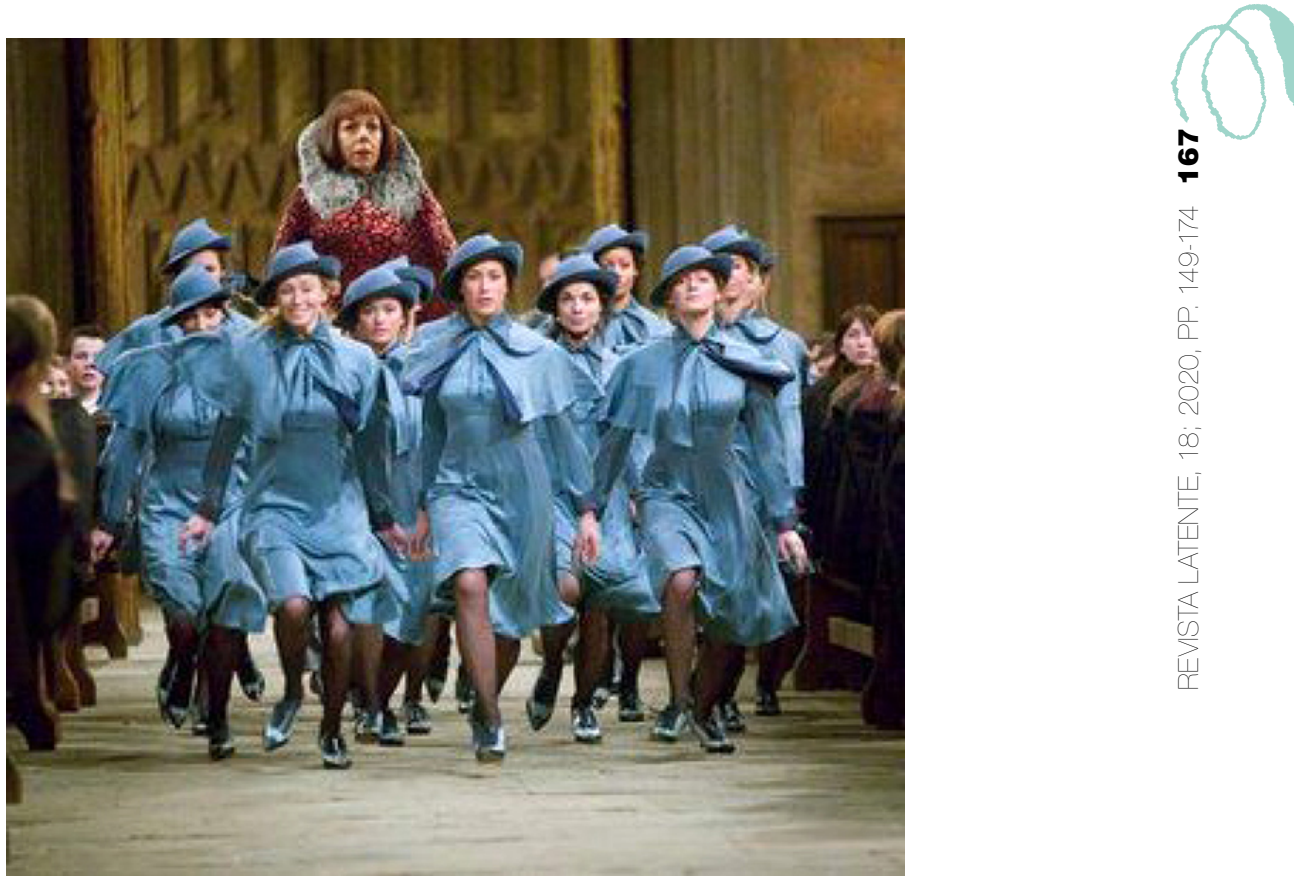

Fig. 3. Baile de entrada de las alumnas de Beauxbatons. Fotograma de Harry Potter y el Cáliz de Fuego, 2005. 


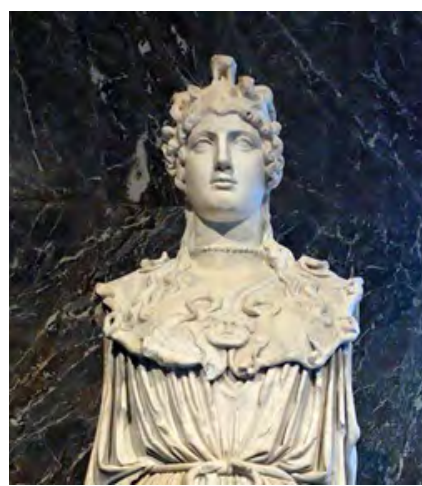

Fig. 4. Detalle de una copia de Atenea Partenos. Museo del Louvre.

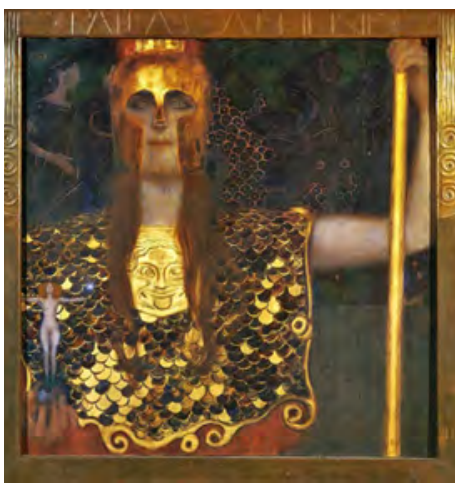

Fig. 5. Palas Atenea.

Gustav Klimt, 1898.

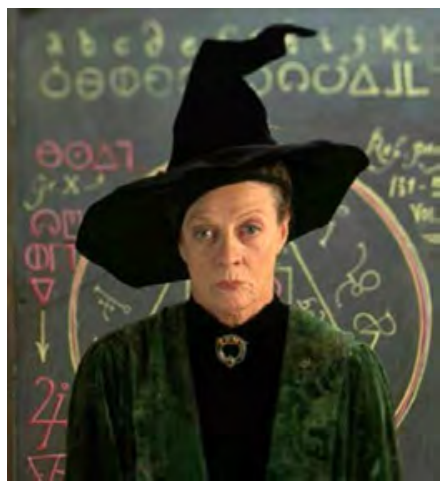

Fig. 6. Minerva McGonagall.

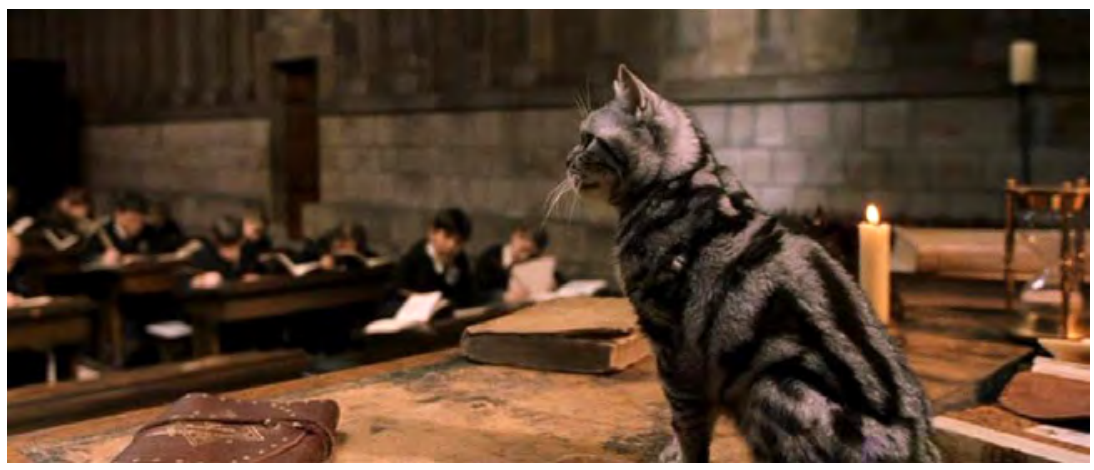

Fig. 7. La profesora McGonagall transformada en gato. Fotograma de Harry Potter y la piedra filosofal, 2001. 


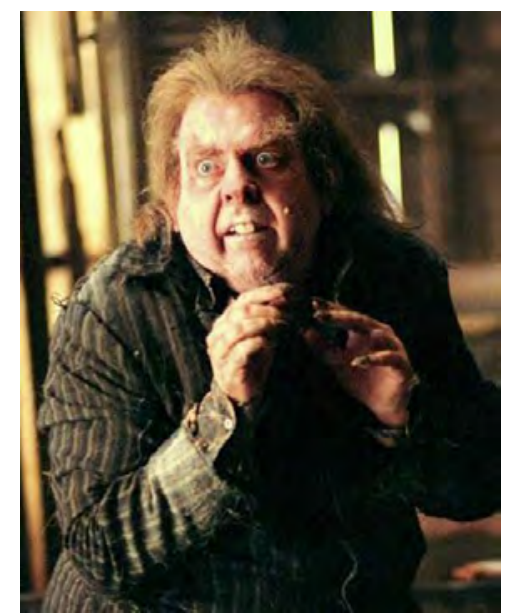

Fig. 8. Peter Pettigrew. Fotograma de Harry Potter y el Prisionero de Azkaban, 2004.

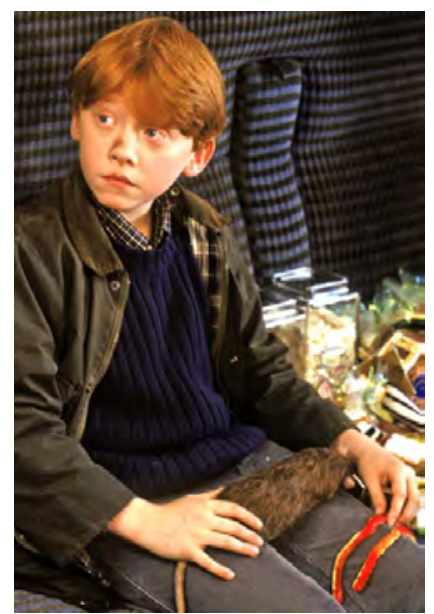

Fig. 9. Peter Pettigrew en su forma de rata junto con Ronald Weasley en el Hogwarts

Express. Fotograma de Harry Potter y la piedra filosofal, 2001.
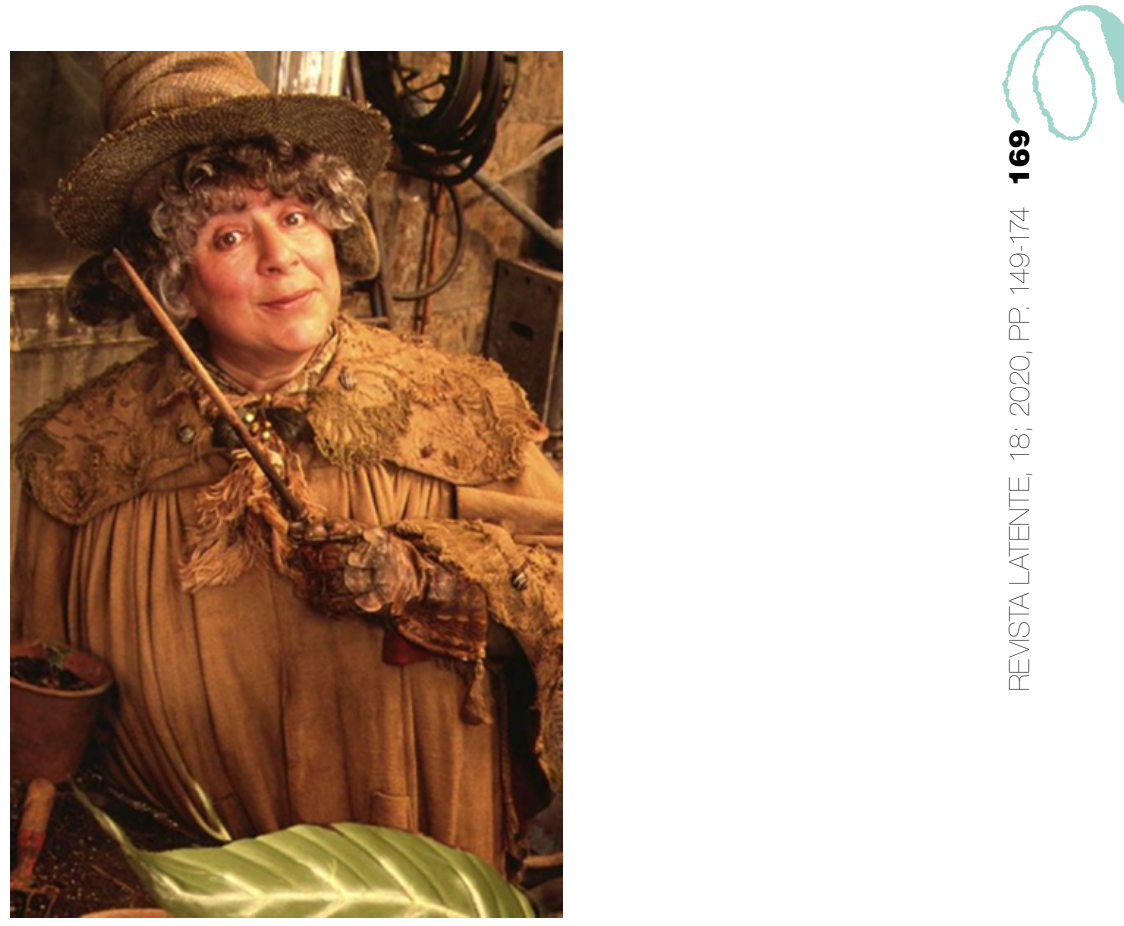

Fig. 10. Profesora Pomona Sprout. 


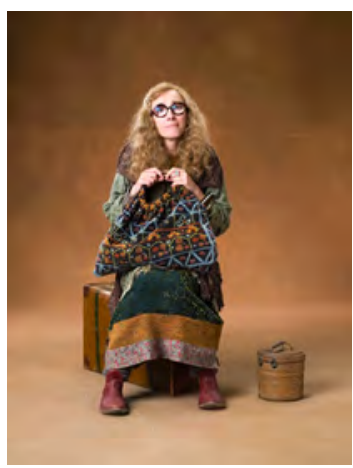

Fig. 11. Profesora Sybill Trelawney.

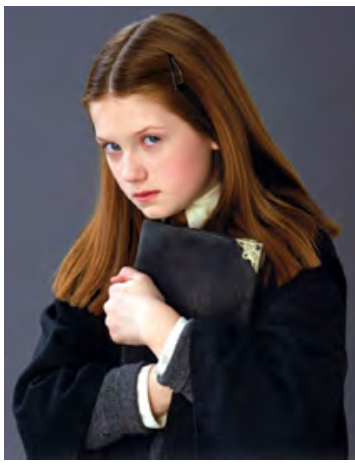

Fig. 13. Ginny Weasley. Imagen promocional para Harry Potter y la Cámara de los Secretos, 2002.

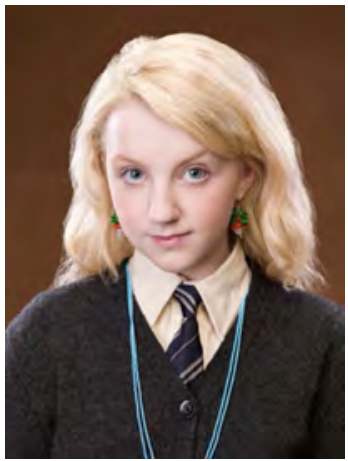

Fig. 15. Luna Lovegood.

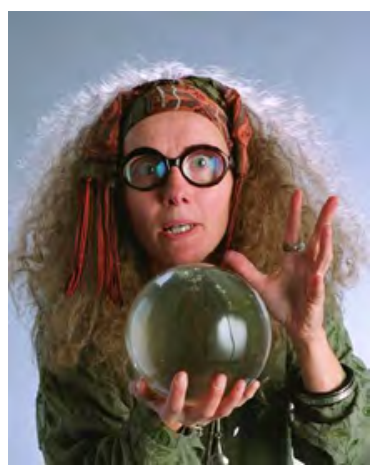

Fig. 12. Profesora Sybill Trelawney.

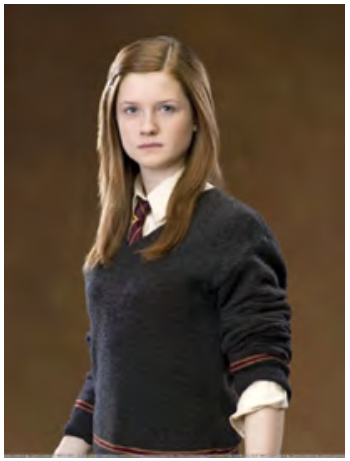

Fig. 14. Ginny Weasley. Imagen promocional para Harry Potter y la Órden del Fénix, 2007.

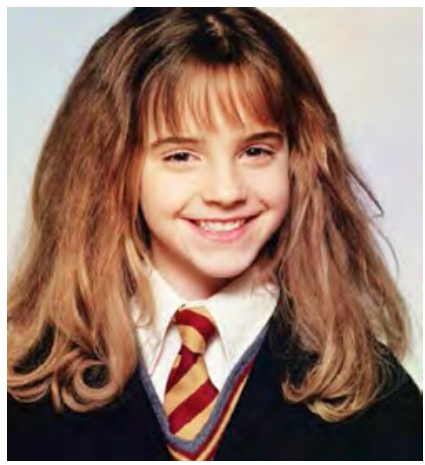

Fig. 16. Hermione Granger en una foto promocional para Harry Potter y la piedra filososal, 2001. 


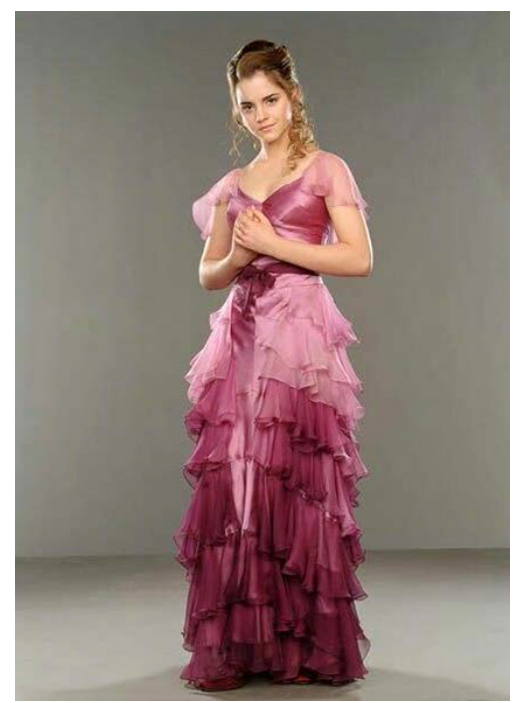

Fig. 17. Hermione Granger vestida para el Yule Ball en Harry Potter y el cáliz de Fuego, 2005.

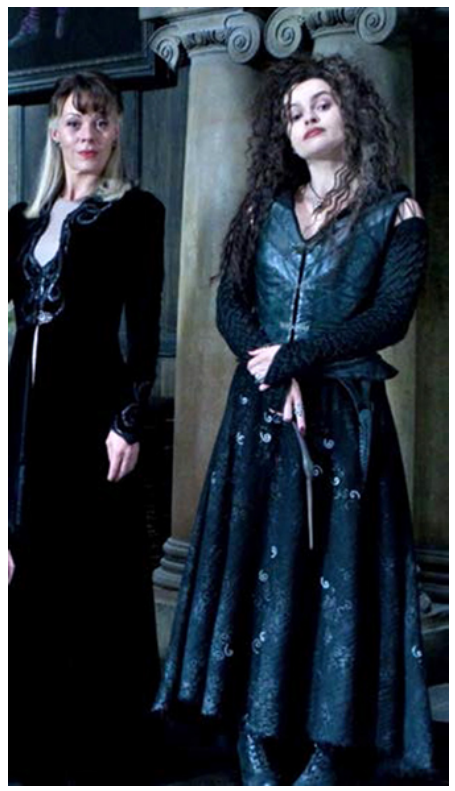

Fig. 19. Narcissa Malfoy \& Bellatriz Lestrange durante el rodaje de Harry Potter y las reliquias de la muerte Parte 1, 2010.

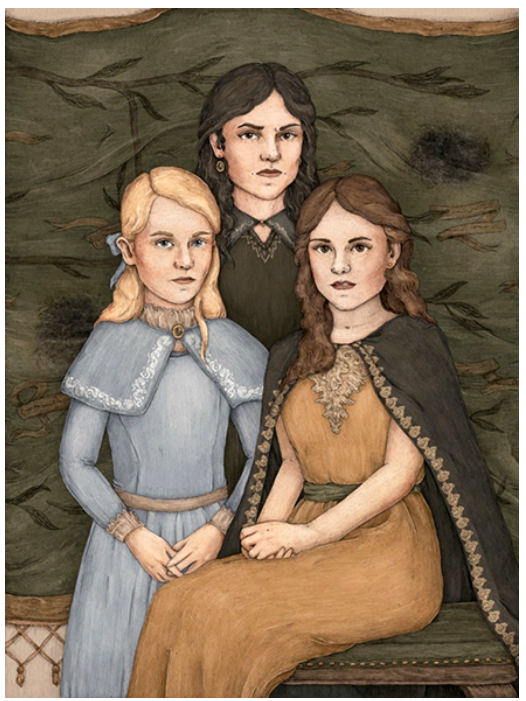

Fig. 18. Narcissa, Bellatriz \& Andromeda Black. Ilustración de wizardingworld, 2018.

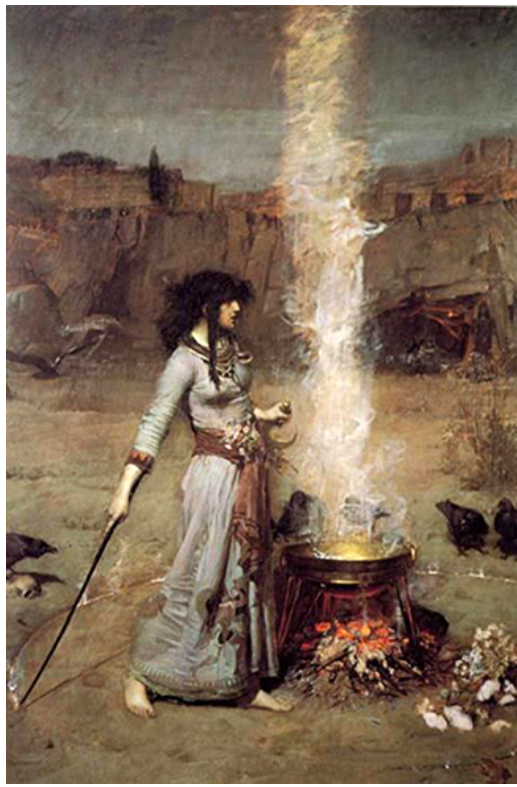

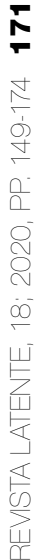

Fig. 20. The magic circle. John William Waterhouse, 1886. 


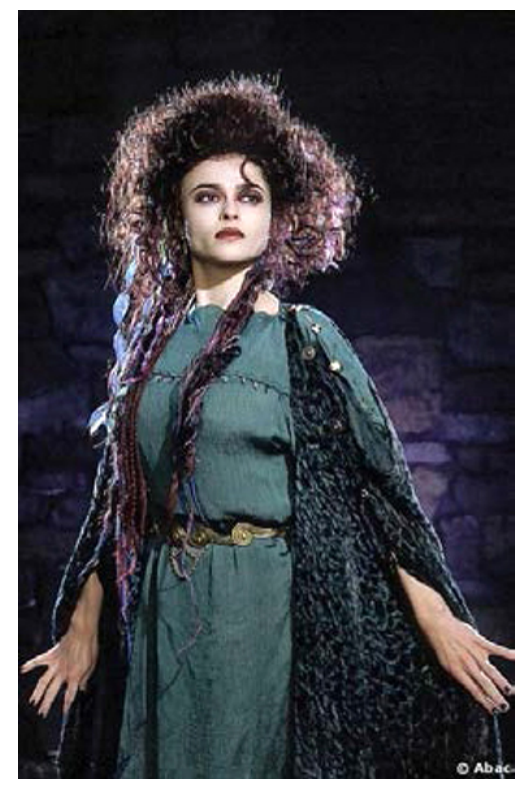

Fig. 21. Helena Boham Carter caracterizada como Morgana Le Fay en la miniserie Merlin, 1998.

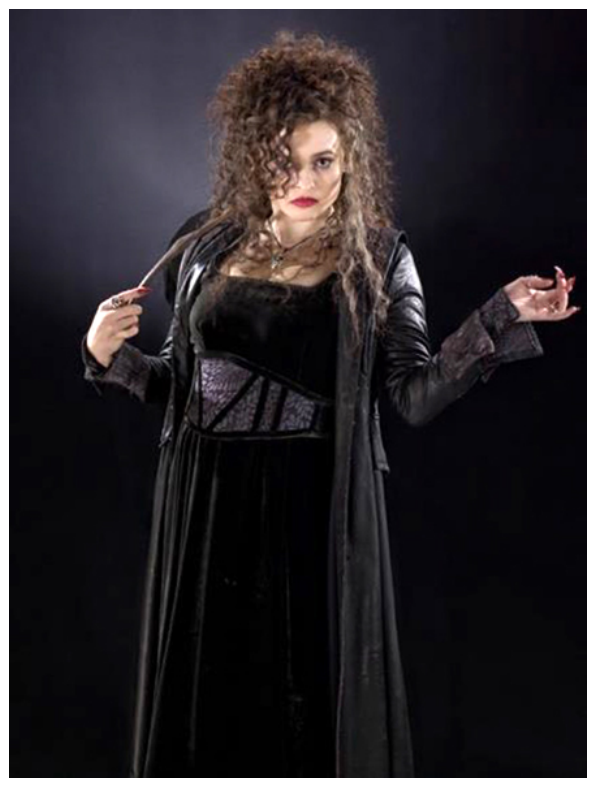

Fig. 22. Helena Boham Carter caracterizada como Bellatrix Lestrange en la saga Harry Potter, 2001-2011.

\section{OBRAS DE JK ROWLING}

Rowling, J.K. (1997): Harry Potter y la piedra filosofal. [Versión electrónica], Barcelona, Salamandra.

Rowling, J.K. (1999): Harry Potter y el prisionero de Azkaban. [Versión electrónica], Barcelona, Salamandra.

Row ling, J.K. (2000): Harry Potter y el cáliz de fuego. [Versión electrónica], Barcelona, Salamandra. Row Ling, J.K. (2003): Harry Pottery la Orden del Fénix. [Versión electrónica], Barcelona, Salamandra. Rowling, J.K. (2007): Harry Potter y el Cáliz de Fuego, [Versión electrónica], Barcelona, Salamandra. 


\section{BIBLIOGRAFÍA}

Bornay, E. (2009): Arte se escribe con $M$ de mujer, Barcelona, Sd. Ediciones.

Burn, A. (2006): «Multi-text magic: Harry Potter in book, film and videogame», en Collins, F.M. \& Ridgman, J., Turning the page: children's literature in performance and the Media, Germany, Peter Lang.

Cingolani, C. (2012): An analysis of names in Harry Potter's novels (BA Dissertation), Universidad de Belgrano, Buenos Aires, p. 28.

Colbert, D. (2008): Magical worlds of Harry Potter. A treasury of myths, legends and fascinating facts, Nueva York, The Berkley Publishing Group, pp. 245, 248.

Edwards, B.L. (ed.) (2007): CS. Lewis. Life, Works, and Legacy (IV Volume: Scholar, Teacher and Public Intellectual), London, Praeger Perspectives.

Ehrenheim, N. (2016): Girls on Fire. Female development in young adult literature in the 21st Century, Universität Greifswald.

Entrevista de Stephen Fry a JK Rowling para la BBC (Reino Unido, 10 diciembre 2005): https:// www.bbc.co.uk/programmes/b0076w0r.

Ferreras Savoye, D. (2014): Lo fantástico en la literatura y en el cine, Madrid,ACVF Editorial.

Gladstein, M. (2017): «Feminism and Equal Opportunity: Hermione and the Women of Hogwarts», en Baggett, David and Klein, Shawn E., Harry Potter and Philosophy. If Aristotle ran Hogwarts, Chicago, Open Court.

Grimal, P. (2008): Diccionario de mitología griega y romana, Barcelona, Paidós.

Jung, C. (1970): Arquetipos e inconsciente colectivo, Barcelona, Paidós.

Leyendas medievales. La bruja Morgana Le Fay: Ciclo Artúrico vir. En Leyendas medievales. La cultura del medioevo y sus mitos. 8 de diciembre de 2019 [en línea] http://leyendasmedievales.over-blog.es/2018/09/la-bruja-morgana-le-fay-ciclo-arturico-vii.html, 2020.

Pottermore (2016): All about Minerva McGonagall. Consultado el 26 de abril 2020, de https:// www.wizardingworld.com/features/pottermore-minerva-mcgonagall-infographic.

Pottermore (2017): Unsung heroes: Fleur Delacour. Consultado el 30 de marzo de 2020, de https:// www.wizardingworld.com/features/unsung-heroes-of-harry-potter-stories-fleur-delacour.

Pottermore (2017): Unsung heroes: Pomona Sprout. Consultado el 26 de abril de 2020, de https:// www.wizardingworld.com/features/unsung-heroes-of-harry-potter-stories-pomona-sprout.

Richards, L. (2003): January Profile: JK Rowling. January Magazine, 5.

Rowling, J.K. (2015): Everytime Bellatrix Lestrange gave us nightmares. Consultado el 2 de abril de 2020, de https://www.wizardingworld.com/features/every-time-bellatrix-lestrange-gave-us-nightmares.

Rowling, J.K. (2015): Sybill Trelawney. Consultado el 26 de abril de 2020, de https://www.wizardingworld.com/writing-by-jk-rowling/sybill-trelawney.

Row LING, J.K. (2016): The chapter that made us fall in love with... Ginny Weasley. Consultado el 30 de marzo de 2020, de https://www.wizardingworld.com/features/chapter-that-madeus-fall-in-love-with-ginny-weasley. 
Rowling, J.K. (2016): Things you may not have noticed about Hermione. Consultado el 1 de abril de 2020, de https://www.wizardingworld.com/features/things-you-may-not-have-noticed-about-hermione.

Rowling, J.K. (2017): In defence of Sybill Trelawney. Consultado el 31 de marzo de 2020, de https:// www.wizardingworld.com/features/in-defence-of-sybill-trelawney.

Rowling, J.K. (2017): The importance of Hermione Granger. Consultado el 2 de abril de 2020, de https://www.wizardingworld.com/features/importance-of-hermione-granger.

Rowling, J.K. (2018): Andromeda, Narcissa and Bellatrix. A tale of three sisters. Consultado el 2 de abril 2020, de https://www.wizardingworld.com/features/andromeda-narcissa-and-bellatrix-a-tale-of-three-sisters.

Rowling, J.K. (2018): Things you may not have noticed about Luna Lovegood. Consultado el 1 de abril de 2020, de https://www.wizardingworld.com/features/things-you-may-not-havenoticed-about-luna-lovegood.

SPENCER, R.A. (2015): Harry Potter and the Classical World. Greek and Roman allusions in JK Rowling's modern epic. Carolina del Norte: McFarland.

Sмiтн, K. (2008): Females and Harry Potter: Not all that empowering, by Ruth Mayes-Elma. Gender and Education, 20(6), 665-666.

Stone, R. (2016): Las dulces Selkies: las grandes olvidadas de los mitos del mar. Consultado el 31 de marzo de 2020, de https://www.ancient-origins.es/noticias-general-mitos-leyendas-europa/las-dulces-selkies-las-grandes-olvidadas-los-mitos-mar-003674.

Walters, James (2011): Fantasy Film: a critical introduction, New York, Berg.

Waltz, R.B. (2016): On Myth and Magic, United States, Loomis House Press. 